\title{
Familial supravalvular aortic stenosis: a genetic study
}

FRANCESCO CHIARELLA*, FRANCA DAGNA BRICARELLI†, GABRIELE LUPI*, PAOLO BELLOTTI*, STEFANO DOMENICUCCI*, AND CARLO VECCHIO*

From ${ }^{*}$ the Division of Cardiology and +Centre for Human Genetics, EO Ospedali Galliera, Genoa, Italy.

SUMMARY Supravalvular aortic stenosis (McKusick 18550) is a rare hereditary condition with autosomal dominant transmission. However, the available data have been limited to small familyin groups which do not allow the definition of the degree of penetrance of the disease. The present $i$ study describes a large family with a high frequency of supravalvular aortic stenosis including five $0_{\circ}^{\circ}$ generations and 80 subjects, the largest family group with this disease studied so far. The studyo was carried out prospectively in 66 subjects (clinical examination, ECG, M mode and two dimensional echocardiography). In 14 subjects available data were examined retrospectively. T In 10 patients cardiac catheterisation was performed (prospective study in eight).

The disease was present in $36(45 \%)$ of the 80 subjects investigated, on the basis of clinical, echocardiographic, and haemodynamic (when available) criteria. The disease was found to be severe in eight cases $(22 \%)$, moderate in six cases $(17 \%)$, mild in $13(36 \%)$, and undefined in $\vec{\odot}$ eight $(22 \%)$ patients. In one case $(3 \%)$, multiple pulmonary stenoses were noted in the absence. of supravalvular aortic stenosis. Genetic analysis of these data shows, for the first time, the degree of penetrance of the supravalvular aortic stenosis trait $(\mathrm{K}=0 \cdot 86)$ and confirms that it is transmitted with incomplete penetrance and variable expressivity.

In 1964 Eisenberg et al $^{1}$ described an infrequent familial form of supravalvular aortic stenosis (SVAS) without unusual facies or mental retardation. These observations were followed by a few reports of single pedigrees in which SVAS was identified in members of successive generations in a pattern consistent with autosomal dominant inheritance. ${ }^{2-9}$ Nevertheless, the genetic features of the syndrome remained incompletely defined owing to the difficulty in collecting an adequate number of cases. Echocardiography permits non-invasive, accurate, and direct visualisation of the supravalvular portion of the aorta. Furthermore, the recent availability of portable echocardiographic systems allows rapid evaluation of patients and screening of relatives in their homes, and thus makes it possible to perform large epidemiological studies.

In the present investigation, we have defined the patterns of genetic transmission of SVAS and its related vascular abnormalities in a large family group of 80 subjects. The purpose of this study was to define for the first time the penetrance and the expressivity of the phenotype of SVAS.

Received for publication 14 March 1988.

Revised version accepted for publication 24 June 1988

\section{Family history}

We examined the last five generations of a family of Ligurian origin that emigrated in 1540 , with a Genoese colony, to the Tunisian coast for corab fishing, and subsequently transferred in 1760 to ao southern island in the Sardinian archipelago. This group was isolated from the surrounding localis population for historical reasons and remained endogamous and closely knit as is proved by theo distinctive dialect used by the forefathers and still in use today. ${ }^{10} 11$

Eighty subjects in five generations of a family with age range from one to 92 years, were studied,$\infty$ 44 of them $(55 \%)$ were males. A prospective study was carried out on 66 of the 80 patients. AN retrospective study was carried out on 14 deadpatients. For these subjects a detailed search was undertaken, including interview of relatives and physicians, and review of medical records andes clinical documentation (cardiac catheterisation data in two patients, report of surgery in one of them).

\section{Methods}

The prospective study included physical examina- 
tion independently performed by two physicians (66 cases), ECG and $M$ mode and two dimensional echocardiography (61 cases), cardiac catheterisation (eight cases), and surgical repair (four cases).

\section{ECHOCARDIOGRAPHIC EXAMINATION}

All echocardiographic examinations were performed by the same operator and included, as well as a standard approach, cross sectional imaging obtained with the patient in a left lateral position where inclination was clearest for observation in longitudinal section of the aortic valve and supravalvular tract complex.

Detection of obstruction comprised visualisation of the decrease in diameter of the vessel (fig 1) where this was greater than that usually found above the aortic root. ${ }^{12}$ Fifty-two examinations were carried out using a transportable OTE Biomedica mechanical sector scanner with a $3.5 \mathrm{MHz}$ transducer. This equipment made it possible to examine at home those family members in which a hospital evaluation was not feasible. Nine echocardiograms were obtained in our laboratory using an ATL Mark 300 mechanical sector scanner with a $3 \mathrm{MHz}$ transducer. The videotaped echocardiograms were rerecorded on a Sony U-matic videotape VO-5800 PS and were reviewed in real time, slow motion, and frame by frame stop image by two independent observers who were unaware of each other's interpretations. Agreement between two observers was required for a diagnosis of SVAS and for the detection of associated abnormalities.

In two cases $(2.9 \%)$ disagreement was resolved by consensus.

\section{DIAGNOSTIC CRITERIA}

Diagnosis of SVAS was established by the presence of the following criteria. (1) Echocardiographic documentation of supravalvular aortic stenosis distal to the valvular cusps; and (2) systolic ejection murmur in the aortic area, radiating to the carotid arteries.

Furthermore, cardiac catheterisation, performed in 10 cases, showed the presence of a transaortic gradient in six of them. The degree of severity of SVAS was estimated according to the criteria given in table 1.

Diagnosis of pulmonary stenosis was based on the detection of angiographic features consistent with this abnormality. The presence of a systolic murmur in the pulmonic area was not considered diagnostic since the aortic origin of such a finding could not be excluded.

\section{GENETIC STUDY}

The family pedigree, covering five generations, is shown in fig 2.

The estimate of the penetrance of the SVAS phenotype was made by calculating the proportion of affected offspring divided by half the total number of offspring, all sibships being included. ${ }^{13}$

\section{Results}

DIAGNOSIS OF SVAS

Data from affected subjects are reported in table 2 .

TABLE 1 Criteria used to evaluate the degree of stenosis.

\begin{tabular}{llll}
\hline & \multicolumn{3}{l}{ Degree of stenosis } \\
\hline & $\begin{array}{l}\text { Systolic } \\
\text { murmur }\end{array}$ & $\begin{array}{l}\text { Aortic } \\
\text { narrowing } \\
(2 D \text { echo })\end{array}$ & $\begin{array}{l}\text { Haemodynamic } \\
\text { gradient }\end{array}$ \\
\hline $\begin{array}{lll}\text { Mild } \\
\text { Moderate }\end{array}$ & $1-2 / 6$ & + & $<30$ \\
Severe & $3 / 6$ & ++ & $30-60$ \\
\hline
\end{tabular}

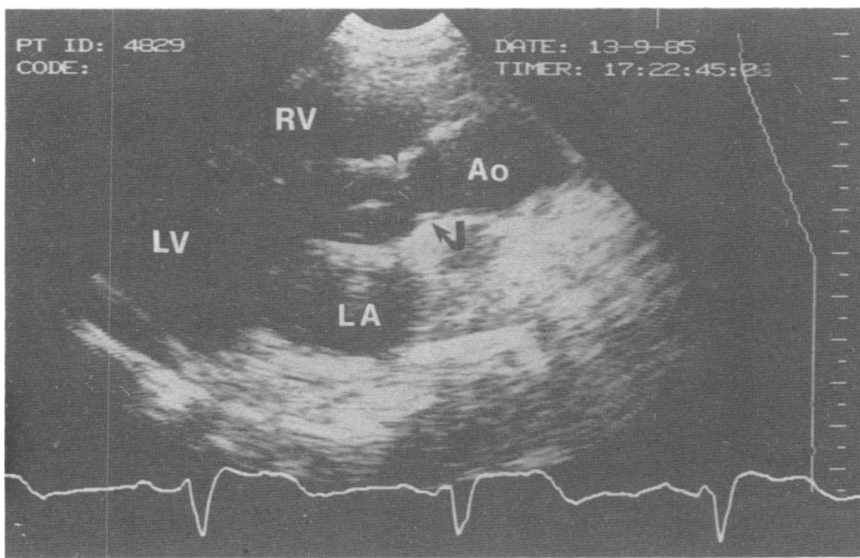

FIG 1 Two dimensional echocardiographic long axis view of patient $I V \cdot 39$. Severe narrowing of the aortic diameter distal to the sinuses of Valsalva (arrows) can be observed ( $A o=$ aortic root; $L A=$ left atrium; $L V=$ left ventricle; $R V=$ right ventricle). 
Prospective study

A diagnosis of SVAS was documented in 26 patients, all of whom had both clinical and echocardiographic evidence of the disease (haemodynamic evaluation in eight of them). The presence of the aortic abnormality was excluded in the remaining 40 patients. Four patients with SVAS underwent surgery (successful repairs in three).

\section{Retrospective study}

Retrospective diagnosis of SVAS was made in nine $\frac{\text { Tे }}{\widetilde{T}}$ dead patients $(\mathrm{I} \cdot 1, \mathrm{II} \cdot 3$, III $\cdot 9$, III $\cdot 16$, III $\cdot 17$, IV $\cdot 18$,

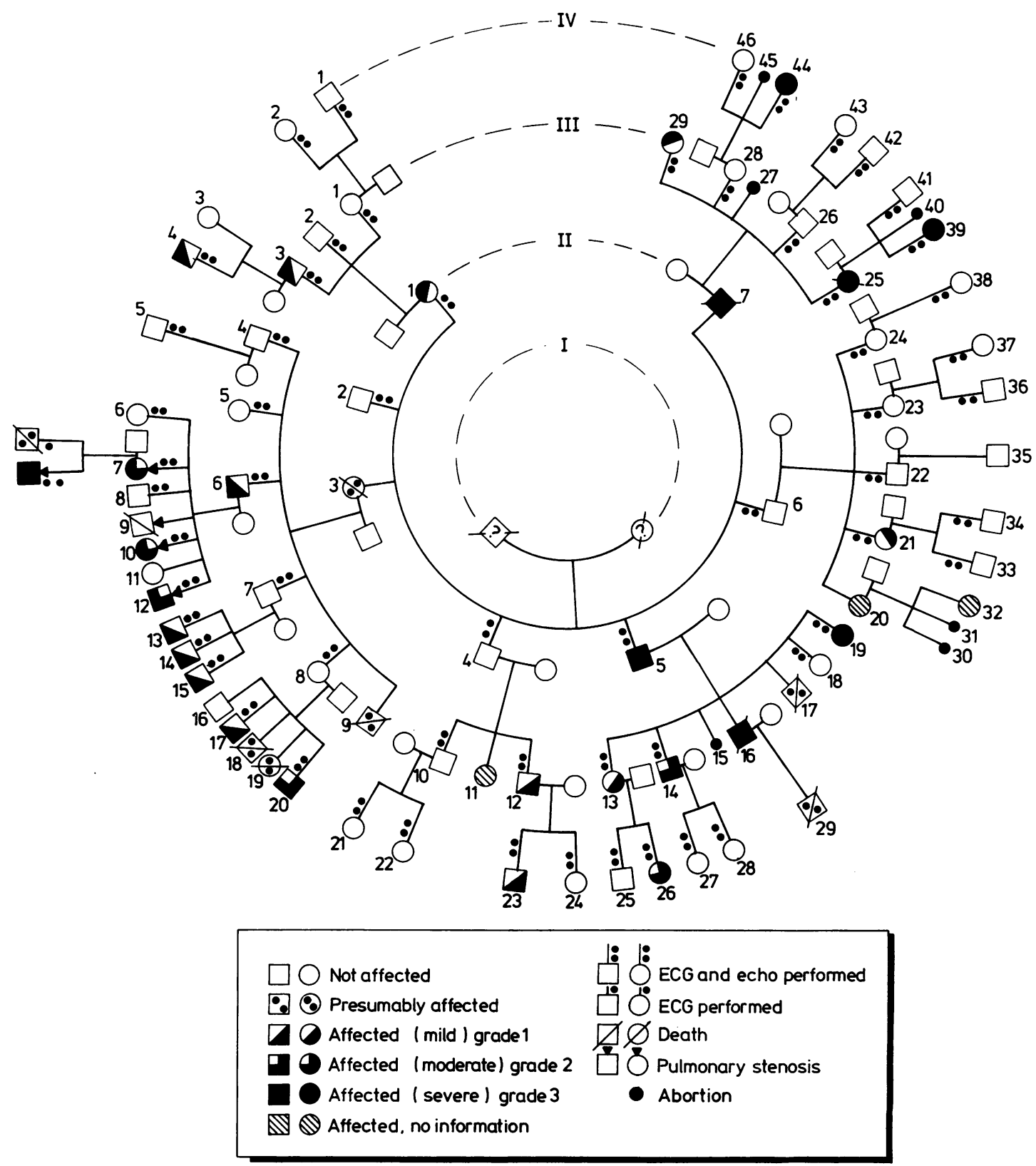

FIG 2 Family pedigree. Affected subjects refer to patients in table 2. 
Familial supravalvular aortic stenosis: a genetic study

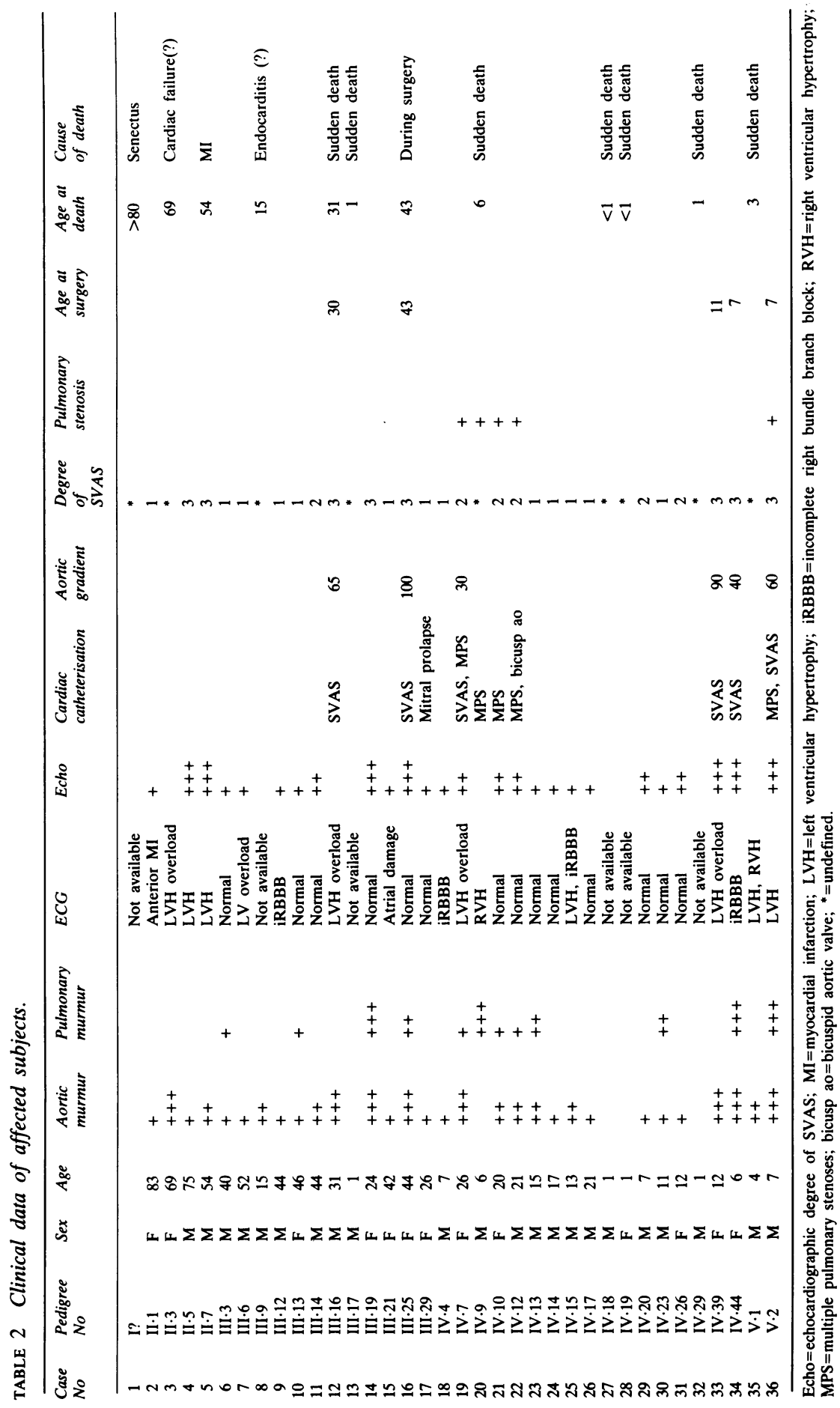


IV 19 , IV 29 , and V·1). In one case (III-16) evidence of SVAS was based on the results of cardiac catheterisation and surgical repair. In three cases (II·3, III.9, and V·1) evidence of SVAS was based on the clinical diagnosis of aortic stenosis made by a cardiologist and the ECG evidence of LV hypertrophy. In another four cases (III $\cdot 17$, IV 18 , IV.19, and IV.29), a history of sudden death in the first year of life was the only fact consistent with the presence of serious congenital heart disease. Finally, one of the founders of the family group studied must necessarily be considered a heterozygous carrier of the SVAS gene.

In three cases (III·11, III·20, and IV·32), the lack of adequate information made the diagnosis of the disease impossible, even on a retrospective basis.

Degree of severity of SVAS

The degree of SVAS was estimated to be mild in 13 patients $(36 \%)$, moderate in six $(17 \%)$, and severe in eight $(22 \%)$. In the remaining eight patients $(22 \%)$ the degree of stenosis could not be determined.

MULTIPLE PULMONARY STENOSES

In five of the 10 patients who underwent cardiac catheterisation, multiple pulmonary stenoses were observed; in one case (IV.9) this abnormality was noted in the absence of SVAS. The degree of pulmonary stenosis on angiographic examination was defined as mild in two patients, moderate in two, and severe in one.

\section{GENETIC EVALUATION}

The large number of family members affected and the accuracy of the diagnostic approach made it possible to evaluate the gene segregation of SVAS. Transmission occurs through an autosomal dominant gene with incomplete penetrance (II.4, II 6 , III $\cdot 7$, III $\cdot 8$, and III.28) and variable expressivity (mild, moderate, or severe degree of stenosis). Moreover, both sexes appear to be heterozygous for the SVAS gene without preferential selection. In fact, the features of the disease were present (second, third, and fourth generations) in 20 males and 13 females, even though the degree of aortic abnormality was different; three males and two females were unaffected carriers of the gene. The sex ratio (second, third, and fourth generations) for carriers of the SVAS gene is 1.5 (23 males and 15 females) and the male/female ratio is 1.2 (41 males and 35 females). Table 3 gives the penetrance coefficient calculation for the SVAS trait; there are four affected subjects out of seven in the second generation, 12 out of 27 in the third, and 17 out of 42 in the fourth, giving a total of 33
TABLE 3 Penetrance coefficient calculation for the SVAS $\overrightarrow{\vec{\sim}}$ trait.

\begin{tabular}{|c|c|c|}
\hline Offspring & Subjects & Affected \\
\hline II & 7 & 4 \\
\hline III & 27 & 12 \\
\hline IV & 42 & 17 \\
\hline Total & 76 & 33 \\
\hline \multicolumn{3}{|c|}{$K=\underline{\text { Offspring affected }}=\underline{33}=0.86$} \\
\hline \multicolumn{3}{|c|}{$K=\frac{1 / 2 \text { Total offspring }}{38}=0.86$} \\
\hline
\end{tabular}

affected out of a total of 76 subjects. The penetrance coefficient is, therefore, 0.86 , that is, $86 \%$ of the carriers of the gene show clinical evidence of the disease.

\section{Discussion}

SVAS was described for the first time in 1930 by an $\overrightarrow{7}$ Italian pathologist. ${ }^{14}$ The disease is an unusual form ${ }^{\mathbb{D}}$ of obstruction of the ascending aorta and has been? recognised with increasing frequency over the last $30 \stackrel{\text { ڤn }}{=}$ years. $^{1-9}$ 15-17 In studies on the types of stenosis $\overrightarrow{-}$ occurring in the region of the aortic valve, supra- $\infty$ valvular aortic stenosis has represented between. $0.6 \%$ and $6 \%$ of cases examined. ${ }^{12}$ SVAS sometimes appears sporadically, but it is more frequently found in familial form.

Two different familial forms have been found. The first and more frequent is associated with 'elfin $\mathbb{\perp}^{\mathbb{2}}$ face' and mental retardation and was first described $\vec{\Rightarrow}$ by Williams $e t a^{15}$ and Beuren et al. ${ }^{16}$ The second 3 and less frequent form, first described by Eisenberg? $e t a l^{1}$ and later by Underhill $e t a l^{8}{ }^{8}$ is characterisedo by normal facial features and intelligence.

From an embryonic point of view, this disease may be the result of hypoplasia of the aortic saco causing a stretching of the connection point between the two aortic arch segments. ${ }^{9}$ In both Williams and Eisenberg's syndromes, the supravalvular aortic alterations are only a part of the dysembryo-? genetic picture: associated alterations have been reported, including multiple pulmonary vesse름 stenosis. $^{346815-18}$ Given the importance of these associated conditions, McKusick ${ }^{5}$ has recentlyo stated that "it can be argued that supravalvular aortic stenosis is an inadequate or inappropriate designation".

Genetic transmission of Williams' syndrome was described by Grimm and Wesselhoeft ${ }^{17}$ in their study of 128 families. For the Eisenberg form however, only two studies have supplied an adequate number of cases: the first ${ }^{2}$ described threes generations of a family with six members with $\mathbb{Q}$ SVAS; the second ${ }^{8}$ studied two generations of family with six cases of SVAS.

In the family we studied, the characteristics of the 
Eisenberg form were present, including cases of SVAS, of multiple pulmonary stenoses, and of a combination of the two. The fact that the family have been island dwellers for several centuries, and are consequently endogamous, explains the unusually high number of patients studied. Although no consanguineous marriages have taken place over the last five generations, it can be assumed that this was not the case before. This supposition is based on information gathered from second generation family members, the General Registry, and local records. ${ }^{10}$

According to Grimm and Wesselhoeft, ${ }^{17}$ both the Williams form and the Eisenberg form of SVAS may be found together in a single family, but none of our subjects suffered either from mental retardation or alteration of facial features.

Our cases would appear to conform entirely to the Eisenberg syndrome. The identity of this form of the disease, about which some doubt has recently been expressed, ${ }^{5}$ would seem, therefore, to be confirmed. Our family would certainly not appear to confirm the suggestion that all SVAS cases should be classified under Williams' syndrome.

Recent progress in the field of echocardiography has made a non-invasive assessment of SVAS possible, first through the use of the $M$ mode technique ${ }^{19-21}$ and later using the two dimensional system. ${ }^{12}$ The reliability of this technique for qualitative and quantitative evaluation of SVAS has recently been shown by Vogt et al. ${ }^{22}$ The two dimensional system enabled us to distinguish different degrees of aortic narrowing and to study all the members of the family group, thus making it possible to gather sufficient information for genetic evaluation. The Doppler examination, which might have given further information, was not available at the time of the study.

Weyman et $\mathrm{ll}^{12}$ have pointed out that the ascending aorta may be of varying dimension in normal subjects, ${ }^{12}$ and therefore, in order to avoid false positive diagnoses where a mild stenosis was indicated echocardiographically, SVAS was considered present only when this narrowing was associated with a systolic ejection murmur recognised by two independent observers.

Out of the 10 patients who underwent haemodynamic examination, SVAS associated multiple pulmonary stenoses were found in four cases and isolated multiple pulmonary stenoses in one. Since only $13 \%$ of the family underwent this examination, the global incidence of this associated pathology might have been underestimated. However, in the absence of clinical indications for cardiac catheterisation, it was not considered ethically justifiable for research purposes only to refer other members of the family for an invasive procedure.
Data could not be obtained from three subjects. This is probably of little importance, however, given the total number of cases studied.

Grimm and Wesselhoeft ${ }^{17}$ and other authors ${ }^{2} 8$ have already observed that the autosomal dominant Mendelian trait of SVAS is transmitted genetically with incomplete penetrance and variable expressivity of the phenotype. Until now, however, the penetrance coefficient has never been calculated. The present study confirms the type of Mendelian transmission, determines its expression with greater accuracy, and calculates the penetrance coefficient.

\section{Conclusion}

Our study confirms that SVAS is transmitted genetically and that the pattern of inheritance is consistent with an autosomal dominant trait with variable expressivity and penetrance. The penetrance coefficient calculated for this family is $0 \cdot 86$. The clinical picture, characterised by SVAS and multiple pulmonary stenoses, without mental retardation or other dysmorphic features, agrees with the form described by Eisenberg, is quite different clinically to that described by Williams $e t a l^{15}$ and Beuren et al, ${ }^{16}$ and provides information regarding the transmission of the disease.

The factors underlying the specific defect of SVAS and the genetic and environmental background $^{23}$ of the two forms of the disease still remain unknown. Future advances in molecular genetics will certainly help to clarify whether the two forms of SVAS (Eisenberg's syndrome and WilliamsBeuren syndrome) are different expressions of the same mutant gene or mutations at two distinct genetic loci.

The authors are indebted to Professor Victor McKusick for his advice, suggestions, and supervision during preparation of the manuscript.

\section{References}

${ }^{1}$ Eisenberg R, Young D, Jacobson B, Boito A. Familial supravalvular aortic stenosis. Am J Dis Child 1964;108:341-7.

2 Logan WF, Jones EW, Walker E, Coulshed N, Epstein EJ. Familial supravalvular aortic stenosis. Br Heart $J$ 1965;27: 547-59.

${ }^{3}$ McDonald AH, Gerlis LM, Sommerville J. Familial arteriopathy with associated pulmonary and systemic arterial stenosis. Br Heart J 1969;31:375-85.

4 Strong WB, Perrin E, Liebman J, Silbert DR. Systemic and pulmonary artery dysplasia associated with unexpected death in infancy. $J$ Pediatr 1970;77:233-8.

5 McKusick VA. Mendelian inheritance in man. Baltimore: Johns Hopkins University Press, 1986.

6 O'Connor WN, Davis JB, Geissler R, Cottrill CM, Noonan J, Todd EP. Supravalvular aortic stenosis. Clinical and pathologic observations in six patients. Arch Pathol Lab Med 1985;109: 179-85. 
${ }^{7}$ Beitzke A, Becker H, Rigler B, Stein JI, Suppan C. Development of aortic aneurysms in familial supravalvular aortic stenosis. Pediatr Cardiol 1986;6:227-9.

${ }^{8}$ Underhill WL, Tredway JB, D'Angelo GJ, Baay JEW. Familial supravalvular aortic stenosis. Am J Cardiol 1971;27:560-5.

${ }^{9}$ Iglesias A, Oliver J,_Mate I, Gilaguado M, Sobrino JA, Nunez L. Estenosis supraaortica familiar. Presentaciòn de dos casos corregidos mediante una aortoplastia ampliada. Rev Esp Cardiol 1981;34:423-6.

10 Morgavi G. Rievocazioni genovesi. Genova: Bozzi, 1961.

11 Rombi B. Del parlar dialetto "zenovese" nell'isola di S. Pietro. La Regione Liguria 1978;10:65-9.

12 Weyman AE, Caldwell RL, Hurwitz RA, et al. Cross-sectional echocardiographic characterization of aortic obstruction. Supravalvular aortic stenosis and aortic hypoplasia. Circulation 1978;57:491-7.

${ }^{13}$ Stevenson AC, Davison BCC. Genetic counselling. London: Heinemann, 1976:1317-8.

14 Mencarelli L. Stenosi sopravalvolare aortica ad anello. Arch Ital Istol Pat 1930;1:829-41.

15 Williams JC, Barrat-Boyes BG, Lowe JB. Supravalvular aortic stenosis. Circulation 1961;24:1311-8.

16 Beuren AJ, Schulze C, Eberle P, Haarmjanz D, Opitz J. The syndrome of supravalvular aortic stenosis, peripheral pulmonary stenosis, mental retardation and similar facial appearance. $A m J \stackrel{\overrightarrow{\mathrm{N}}}{\overrightarrow{\mathrm{S}}}$ Cardiol 1964;13:471-83.

${ }^{17}$ Grimm T, Wesselhoeft $\mathrm{H}$. The genetic aspects of WilliamsBeuren syndrome and the isolated form of the supravalvular $\bar{\sigma}$ aortic stenosis. Investigation of 128 families. Z Kardiol 1980; $\bar{\omega}$ 69:168-72.

18 Feigl A, Feigl D, Yahini JH, Deutsch V, Neufeld NH. § Supravalvular aortic and peripheral pulmonary arterial stenoses. A report of eight cases in two generations. Isr J Med Sci 1980;16:496-502.

19 Usher BW, Goulden O, Margo JP. Echocardiographic detection of supravalvular aortic stenosis. Circulation 1974;49:1257-61. $\vec{\omega}$

20 Bolen JL, Popp RL, French JW. Echocardiographic features of $\sigma$ supravalvular aortic stenosis. Circulation 1975;52:817-21.

${ }^{21}$ Nasrallah AT, Nihill M. Supravalvular aortic stenosis: echocardiographic features. Br Heart $J$ 1975;37:662-7.

22 Vogt J, Rupprath G, Grimm T, Beuren AJ. Qualitative and quantitative evaluation of supravalvular aortic stenosis by crosssectional echocardiography. Pediatr Cardiol 1982;3:13-7.

${ }^{23}$ Opitz JM. Some comments on penetrance and related subjects. $\bigcirc$ Am J Med Genet 1981;8:265-74.

Correspondence to Professor Carlo Vecchio, Divi- T sion of Cardiology, EO Ospedali Galliera, Via Volta 8, 16128 Genoa, Italy. 